\title{
Evaluation of B7-1 (CD80) and B7-2 (CD86) Costimulatory Molecules and Dendritic Cells on the Immune Response in Leprosy
}

\author{
*Santos, D.O.; **Santos, S.L.; **Esquenazi, D.; ** Nery, J.A.; \\ ${ }^{\star * *}$ Defruyt, M.; ${ }^{* \star *}$ Lorré, K. and ${ }^{* * *}$ Van Heuverswyn, $\mathrm{H}$. \\ * Department of Molecular and Cellular Biology; Institute of Biology; University Federal Fluminense , \\ Av. Barros-Terra ,s/n. Valonguinho, Niterói, RJ. Brasil, CEP20400; \\ ** Leprosy Unit, Oswaldo Cruz Foundation, Av. Brasil , Manguinhos, R.J., Brasil; \\ *** Innogenetics N.V., Industriepark Zwijnaarde 7, box 4, B9052, Ghent, Belgium.
}

[Received: 13 Spt 1999 / Accepted: 2 Oct 2000 ]

Key words: lepromatous leprosy, CD80, CD86, dendritic cells, M. leprae.

The cell activation depends on $\mathrm{T}$ cell antigen receptor binding to antigen plus $\mathrm{MHC}$ and costimulation. The binding of CD28, expressed on the $\mathrm{T}$ cell surface to $\mathrm{B} 7$ (B7-1 or CD80 / B7-2 or CD86) present on the antigen - presenting cells (APCs), determines, in several T cell function models, if activation or anergy follows antigenic stimulation. In leprosy, the role of CD80 and CD86 as costimulatory signal in M. leprae - specific cellular immunity has not yet been defined. We investigated the role of B7-CD28 pathway of T cell activation in the in vitro response to $M$. leprae, following stimulation in the presence of monocytes or dendritic cells (DCs) as APCs.

Monocytes were purified, by cold aggregation, from peripheral blood mononuclear leukocytes (PBMC), isolated from leprosy patients. In order to obtain DCs, the monocytes were cultured in the presence of IL-4 and GM-CSF. T cells were purified from PBMC by negative selection with mABs and C'. The phenotype of the cell populations was monitored by FACS. Lymphoproliferative assays were performed with $\mathrm{T}$ cells, in the presence of monocytes or DCs. The cells were stimulated by M. leprae in the presence of anti - CD80 antibody $(\mathrm{Ab})$ and/or anti - CD86 antibody (Ab) (Innogenetics). In some experiments Il-10, Il-12 and anti-Il-12 $\mathrm{Ab}$ were also added to the culture.

We observed a significantly more efficient APC function for DCs when compared to monocytes in T cell in vitro responses to $M$. leprae. Regardless of the clinical form of Leprosy, the $M$. leprae-specific immune response was markedly reduced in the presence of anti - CD86 Ab. Il-12 increase the immune response to $M$. leprae while IL-10 or anti-IL-12 Ab reduce this response when monocytes or DCs were used as APCs.

*Corresponding author:

Department of Molecular and Cell Biology; Institute of Biology; University Federal Fluminense.

Av. Barros-Terra, s/n. Valonguinho, Niterói, R.J. Brasil. CEP20400

email: dilvani@openlink.com.br

Fax: 0055217195934. 


\section{Introduction}

Leprosy is a chronic infectious disease of human beings that primarily affects the skin, mucous membranes and nerves. Leprosy presents a spectrum of clinical manifestations that correlate with immune responses to the pathogen ${ }^{1)}$. At one end of the spectrum, patients with tuberculoid leprosy display the resistant response that restricts the growth of the pathogen. At the opposite end of this spectrum, patients with lepromatous leprosy (LL) represent extreme susceptibility to $M$. leprae infection. Since the immune system in these two polar groups react completely different upon reinfection or antigen challenge in vitro, it has been suggested that the differentiation into either of the forms of leprosy depends largely on the primary immune response of the host. In leprosy, only little is known about the distinct paterns of cytokine production in correlation to the distinct forms of leprosy and resistance or susceptibility to M. leprae. Recently, Yamamura et al. ${ }^{2)}$ have demonstrated mRNA encoding for Il-12 and gammainterferon in lesions of tuberculoid patients and mRNA encoding for IL-4, IL-5 and IL-10 in lesions of LL patients. These findings suggested that the differentiation of leprosy into a tuberculoid or LL form is correlated with the presence of Th1 or Th2 like cytokines.

It is now clear that $\mathrm{T}$ cells require 2 signals for optimal activation. The first signal is provided by engagement of T cell receptor (TCR) with the antigenic peptide plus major histocompatibility complex (MHC) on antigen-presenting cells (APCs), and thus provides antigen-specificity to the immune response. The second "costimulatory" signal is provided by binding of specific receptors on $\mathrm{T}$ cells with their ligand/s on APCs. The best characterized costimulatory pathway is that provided by $\mathrm{CD} 28$ on $\mathrm{T}$ cell binding to B7-1(CD80) and /or B7-2 (CD86) on dendritic cells (DCs) and monocytes/macrophages - APCs ${ }^{3)}$.

CD28 is a $90 \mathrm{kD}$ homodimeric glycoprotein. It is expressed on the surface of $80 \%$ of all peripheral $\mathrm{T}$ cells ( $95 \%$ of CD4+ cells and $50 \%$ of CD8+ cells) 4). Ligation of CD28 with its counter - receptor promotes cell cycle progression and increases IL-2 production by regulation IL-2 mRNA ${ }^{5)}$. CD28 has a high degree of homology ( $32 \%$ at the amino acid level) to a distinct gene called CTLA- $4^{6}$. Unlike CD28, which is expressed on resting T cells, CTLA4 appears to only be expressed at the cell surface after $\mathrm{T}$ cell activation ${ }^{7}$. CTLA-4 appears to downmodulate immune responses by binding with high affinity to its counter-receptors ${ }^{8}$.

At least two distinct ligands for CD28 and CTLA-4 have been cloned: $\mathrm{CD} 80^{9)}$ and $\mathrm{CD} 86^{10) ; 11)}$ both of which can interact with their counter-receptors, CD28 and CTLA-4 on T cells ${ }^{12)}$, 13), 14) and 15). CD80 is a 45 $60 \mathrm{kD}$ protein expressed on activated, but not resting APCs. After, activation maximum CD 80 mRNA and protein levels occur at 27 and 48-72 hours respectively ${ }^{16}$. The recently identified CD86 molecule shares $25 \%$ amino acid identity with CD80 and is expressed on both resting and activated APCs ${ }^{17), 18)}$. Upon activation, CD86 is expressed earlier ( 6 to 48 hours) and at higher levels than CD80 ${ }^{18)}$, 19). The role of B7 on different APC populations such as DCs and monocytes in the different forms of leprosy strongly points to an important costimulatory role of CD80 and CD86 molecules in T cell activation in leprosy. DC are a small subset of human blood mononuclear cells that are potent stimulators of several $\mathrm{T}$ cell functions. They are much more potent than monocytes or B cells in inducing $\mathrm{T}$ cell responses to a panel of antigens ${ }^{20)}$. In particular, DCs can be triggered by proinflammatory stimuli such as TNF alpha, IL-1 and LPS to mature and to upregulate adhesion and

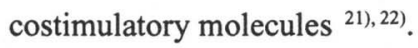

Recent reports indicate that DCs can produce IL-12 23), 24). More recently, Cella et al. ${ }^{25)}$ showed that CD40L is the most potent stimulus in upregulating the expression of CD80 and CD86 molecules on DCs. Here we have studied the role of CD80 and CD86 costimulation in T cell activation in leprosy, in response to M. leprae, with monocytes or DCs as APCs. 
We have tested the possibility that the presentation of $M$. leprae antigens on different APC in the presence or absence of anti - CD80 antibodies and/or anti - CD86 antibodies could lead to either Th1 or a Th2 response.

\section{Materials and Methods}

\subsection{Cell isolation}

Mononuclear cells were obtained from heparinized blood isolated from leprosy patients. They were from Santa Casa de Misericórdia, R.J. Disease classification occurred according to the criteria of Ridley and Jopling ${ }^{1}$. At the time of study, leprosy patients were either untreated or undergoing a specific multidrug chemotherapy (MDT) for leprosy.

Mononuclear cells were also obtained from healthy individuals who had no previous contact with $M$. leprae (volunteers from Innogenetics, Belgium).

\section{2.. PBMC isolation and monocytes purification.}

Obs. All the antibodies, cytokines as well as the reagents used here are LPS free as manufacturer, $\mathrm{s}$ specifications.

Peripheral blood mononuclear cells (PBMC) were isolated by Ficoll-Hypaque sedimentation (density 1077). Enriched monocyte preparations were obtained a two cycles of cold agregation ${ }^{26)}$. Briefly, 5 $x 10^{7}$ PBMC resuspended in RPMI medium (Sigma; UK) with $10 \%$ FCS were incubated during $30 \mathrm{~min}$ at $4^{\circ} \mathrm{C}$ under continuos rocking agitation. Monocytes were then sedimentated spontaneously ( $1 \mathrm{~min}$ on ice). The pellet was resuspended in RPMI medium added of $10 \%$ FCS and, then subject to a new cycle of clumping under agitation at $4^{\circ} \mathrm{C}$. After centrifugation, the pellet was resuspended in fresh medium culture. The resulting cell preparation routinely contained more than $80 \%$ monocytes as assessed by morphology and FACS analysis. The average purity of this monocyte preparation was $80 \%$ (data not shown). A small contamination of CD3+ cells were detected (19\%).

\section{3. $T$ cells purification.}

$\mathrm{T}$ cells were further purified from monocyte depleted PBMC (the supernatant of the cold agregation) by using Lympho-Kwik-Treagent (Lambda Inc., CA,USA). Lymphocytes were resuspended in medium at concentration of $2 \times 10^{7)}$ cells and incubated with $0.8 \mathrm{ml}$ Lympho-Kwik-T reagent for $45 \mathrm{~min}$ at $37^{\circ} \mathrm{C}$. After adding PBS to the top of the tube, the cells were centrifuged for $2 \mathrm{~min}$ at $2000 \mathrm{rpm}$. Purified $\mathrm{T}$ cells were washed once at $1500 \mathrm{rpm}$ for $5 \mathrm{~min}$, and resuspended in culture medium . T cells were more than $99 \%$ positive for CD3 marker. No CD14 positive monocytes were detected (data not shown).

\subsection{Dendritic cells differentiation and Lymphoproliferation test.}

For dendritic cells differentiation studies, the monocytes were cultured at a concentration of $0.5 \times 10^{6}$ cells $/ \mathrm{ml}$ in complete medium. The cells were incubated in $12 \times 75 \mathrm{~mm}$ polystyrene tubes (Becton Dickinson Labware, New Jersey). Then, they were cultured in medium alone; or with rGM-CSF (100 $\mathrm{U} / \mathrm{ml}$; Schering - Plough, Brussels,Belgium) and rIL4 (1000 U/ml, Innogenetics N. V., Ghent, Belgium) as described by Sallusto et al. ${ }^{21)}$. After 07 days at $37^{\circ} \mathrm{C}$, the monocytes cultured without rGM-CSF and IL-4 (control) and monocytes cultured with these cytokines (dendritic cells) were counted and monitored by FACS analysis (stained with FITC anti-CD3 , FITC anti-CD14, PE anti-CD1a, PE anti-CD1b, PE-antiCD1c (Becton-Dickinson,San Jose, CA, USA)), anti$\mathrm{CD} 80 \mathrm{Ab}$, anti-CD86 Ab (Innogenetics N. V. )).

After having the immunophenotype of these cells they were used for proliferation assays. These assays were carried out in triplicate with $10^{5}$ each of antigen presenting cells (monocytes or dendritic cells) and the same concentration of autologous $T$ cells in $200 \mathrm{ul}$ RPMI complete medium in 96 well $\mathrm{U}$ bottom microtitre plates. Controls with whole PBMC were also done.The cells were added or not of $20 \mathrm{ug} / \mathrm{ml}$ M. leprae (Irradiated armadillo-derived Mycobacterium leprae, kindly donated by Dr. Patrick J. Brennam, Colorado State University, USA) with or 
not $1 \mathrm{ug} / \mathrm{ml}$ anti- $\mathrm{CD} 80 \mathrm{Ab}$ (Innogenetics), with or not $1 \mathrm{ug} / \mathrm{ml}$ anti-CD86 Ab (Innogenetics); 20ng/ml IL-10 (Genzyme, USA); 10 ng/ml IL-12(R \& D Systems,UK) or 10ug/ml anti-IL-12 Ab.(R \& D Systems).

Cultures were collected on day six after $16 \mathrm{~h}$ pulse with $1 \mathrm{uCi}^{3} \mathrm{H}$ - thymidine $(5 \mathrm{Ci} / \mathrm{mMol}$, Amersham Life Science, Buckinghamshire, UK) and ${ }^{3} \mathrm{H}$ incorporation determined by liquid scintillation counting.

\subsection{Flow cytometry analysis.}

For immunophenotyping of the cells, whole PBMC, purified monocytes(after 07 days of culture) and dendritic cells (monocytes cultured for 07 days in the presence of GM-CSF and IL-4) were used. In some experiments, dendritic cells generated from monocytes incubated with $M$. leprae cells were also stained. The cells were washed and used for the analysis of CD3 (to stain lymphocytes), CD14 (to stain monocytes), CD1a/ CD1b/ CD1c (to stain dendritic cells). To stain costimulatory molecules, anti - CD80 Ab, anti - CD86 Ab were used. Briefly, $2 \times 10^{5} \mathrm{cell} / \mathrm{ml}$ were resuspended in $10 \mathrm{ul}$ of PBS solution $\mathrm{pH} 7.2$, suplemented with $0.1 \%$ sodium azide and $3 \% \mathrm{BSA}$ ) and incubated with 5ug/ml FITC anti-CD3; 10ug/ml FITC anti CD27; 10ug/ml FITC anti-CD14; $10 \mathrm{ug} /$ $\mathrm{ml} \mathrm{PE}$ [anti-CD1a or CD1b or CD1c]; 1 ug.ml PEbiotylated [anti - CD80 Ab or anti-CD86 Ab during $30 \mathrm{~min}$ at $4{ }^{\circ} \mathrm{C}$, in the dark. After staining, all cells were fixed with $1 \%$ paraformal-dehyde (Sigma) and analysed in a flow cytometer FACScan (Becton \& Dickinson) ${ }^{27)}$. The samples were compensated with appropiate controls for each of two colors. The threshold was set to abort all dead cells and debris as determined by light scatter.

\subsection{Statistical analysis.}

Significance of the difference between the values of the various experimental conditions studied ( $M$. leprae in the presence or not anti-CD80 Ab or anti$\mathrm{CD} 86 \mathrm{Ab}$ ) was evaluated by the Wilcolxon's test 28). According to this test, for conjugated samples and with a significant level of $5 \%(\alpha=0.05)$ we accept or not the differences among the group. Values $>0.05$ means that there is no statistical difference.

Table I. Effects of $M$. leprae on the phenotype of human DC.

\begin{tabular}{|c|c|c|c|c|}
\hline \multicolumn{2}{|c|}{ Surface molecule expression (\% fluorescent dendritic cells / mean fluorescence intensity) } \\
\cline { 2 - 5 } Antibodies & - M.leprae & + M.leprae & - M.leprae & + M. leprae \\
\hline \multirow{2}{*}{ CD14 } & $\frac{2.12}{49}$ & $\frac{5.68}{170}$ & $\frac{0.84}{104}$ & $\frac{2.70}{173}$ \\
\hline CD1a & $\underline{33.38}$ & $\frac{35.32}{198}$ & $\frac{33.12}{374}$ & $\frac{24.94}{246}$ \\
\hline CD1b & $\frac{73}{129}$ & $\frac{68.25}{165}$ & $\frac{84.32}{117}$ & $\frac{79}{172}$ \\
\hline CD1c & $\frac{66.46}{98}$ & $\frac{69}{103}$ & $\frac{70.28}{224}$ & $\frac{76.47}{180}$ \\
\hline CD80 & $\frac{60}{54}$ & $\frac{53.46}{283}$ & $\frac{69}{205}$ & $\frac{56}{197}$ \\
\hline CD86 & $\frac{47}{141}$ & $\frac{45.76}{270}$ & $\frac{48}{209}$ & $\frac{44}{176}$ \\
\hline
\end{tabular}

DC $\left(2 \times 10^{5}\right.$ cells $\left./ \mathrm{ml}\right)$ were cultured for $24 \mathrm{~h}$ in RPMI medium plus $10 \%$ FCS with or not $M$. leprae $20 \mathrm{ug} / \mathrm{ml}$, as described in Methods. DC were then stained with the different mAbs or isotypic controls and surface molecule expression was analysed by FACS. 


\section{Results}

\subsection{Immunophenotyping of resting PBMC; cultured} monocytes and dendritic cells generated from PBMC. Spontaneous expression of CD14, CD1a, CD1b, CD1c, CD80 and CD86 was analysed in a whole PBMC isolated from leprosy patients. PBMC isolated from leprosy patients (lepromatous leprosy-LL; bordeline lepromatous leprosy -BL and bordeline tuberculoid leprosy-BT) spontaneously express the same level of CD80 and CD86 molecules $(11.7 \pm 3$ and $11.5 \pm 3.6 \%$ of fluorescent cells, respectively) compared to the spontaneous CD80 and CD86 expression seen in PBMC isolated from normal individuals $(12.4 \pm 2.5 \%$ of fluorescent cells) .

In order to investigate if $M$. leprae modulate the phenotype of dendritic cells generated from monocytes, we analysed the phenotype of these cells isolated from healthy individuals after incubation in vitro with $M$. leprae. Table I shows that $M$. leprae does not influence the phenotype of dendritic cells generated from monocytes isolated from normal individuals.

\subsection{Lymphoproliferative response (LTT) to M. leprae} by using different cells as APC. Neutralization with anti-CD80 Ab and/or anti CD86 Ab.

Our results show that healthy individuals who had no previous contact with $M$. leprae slightly respond to this antigen in vitro when dendritic cells generated from monocytes were used as APCs (Table II). The figure 1 and 2 show that dendritic cells generated from monocytes isolated from lepromatous or tuberculoid leprosy patients were more efficient APCs than monocytes, for response to $M$. leprae in the presence of autologous T cells $(\alpha<0.05)$. The use of dendritic cells as APC reversed the M. leprae - specific T cell hyporesponsiveness observed in lepromatous leprosy.

Anti-CD80 Ab and anti- CD86 Ab inhibit M. lepraespecific responses in vitro. Anti- $\mathrm{CD} 86 \mathrm{Ab}$ had a more marked blocking effect on $\mathrm{M}$. leprae - induced T cell activation $(\alpha<0.05)$ than anti-CD80 Ab, when monocytes or dendritic cells were used as APCs.

\subsection{Lymphoproliferative response to M. leprae by} using different cells as APCs. Incubation with IL-10 and $I L-12$.

IL-12 enhance the immune response to M. leprae while IL-10 reduce this response when monocytes or dendritic cells were used as APCs in leprosy patients. The treatment with anti-IL-12 Ab also decrease this response (Figure 3). Similar results were found in healthy individuals when dendritic cells were used as APC (Table II).

Table II . Lymphoproliferative response

\begin{tabular}{|c|c|c|c|c|}
\hline \multirow{3}{*}{$\begin{array}{l}\text { Experimental } \\
\text { Conditions }\end{array}$} & \multicolumn{4}{|c|}{$\begin{array}{l}\mathrm{T} \text { cell proliferation in presence of } M \text {. leprae } \\
\text { (stimulation index [SI] = cpm test } / \mathrm{cpm} \text { control) }\end{array}$} \\
\hline & \multicolumn{2}{|c|}{ Whole PBMC } & \multicolumn{2}{|c|}{ Dendritic cells } \\
\hline & Donor 1 & Donor 2 & Donor 1 & Donor 2 \\
\hline M.l. & 1.3 & 0.6 & 1.8 & 2.2 \\
\hline$M . l+\mathrm{IL}-12$ & 1.5 & 1.6 & 5.2 & 4.5 \\
\hline$M . l+I L-10$ & 0.2 & 0.1 & 0.6 & 0.1 \\
\hline M.l. + anti-CD80 Ab & 1.1 & 1.2 & 1.2 & 0.9 \\
\hline$M l+$ anti-CD86 Ab & 0.6 & 0.4 & 0.8 & 0.9 \\
\hline$M l+$ anti-CD80 Ab + anti-CD86 Ab & 0.3 & 0.4 & 0.7 & 0.6 \\
\hline
\end{tabular}

$10^{5}$ PBMC or $10^{5} \mathrm{DC}$ with $10^{5}$ autologous T cells were cultured in the presence or not of M. leprae (M.l.) $20 \mu \mathrm{g} / \mathrm{ml}$, IL-12 $10 \mathrm{ng} / \mathrm{ml}$, IL-10 $20 \mathrm{ng} / \mathrm{ml}$, anti-CD80 Ab $1 \mu \mathrm{g} / \mathrm{ml}$ and anti-CD86 Ab $1 \mu \mathrm{g} / \mathrm{ml}$, as described in METHODS. CPM of unstimulated T cells (without M. leprae stimulation) was 386 for donor 1 and 297 for donor 2 . 


\section{Discussion}

In our hands $M$. leprae does not modify the phenotype of DC generated from monocytes isolated from healthy individuals (Table I). Differently, it have been reported that LPS enhances the expression of CD80 on dendritic cells ${ }^{21)}$ as well as $M$. leprae down regulate the expression of $\mathrm{CD} 80$ and $\mathrm{CD}^{28)}$ on the surface of lymphocytes isolated from healthy individuals ${ }^{29)}$. Normally, healthy individuals who had no previous contact with $M$. leprae do not respond in vitro to this antigen (Table II). However when dendritic cells generated from monocytes are used as APCs, we can see a weak immune response in vitro to $M$. leprae (Table II). This response is exuberantly increased in the presence of IL-12.

IL-12 is, now, recognized as a key factor for the induction of IFN gamma production as well as growth factor for $\mathrm{T}$ cells ${ }^{30)}$. Dendritic cells were recently, described as the main source of IL-12 production ${ }^{23)}$. Perhaps the production of IL-2 is also increased in this case and it could be responsible for the increase of lymphoproliferation in response to $M$. leprae in the presence of IL-12. These factors may favor the involvement of a particular APC as well as the production of special cytokines by either APCs or $\mathrm{T}$ cells directing $\mathrm{Th} 1$ or $\mathrm{Th} 2$ responses.

The ability of dendritic cells to act as potent APCs for induction of $\mathrm{T}$ cell responses to a variety of antigens both in vitro ${ }^{20), 31,32), 33)}$ and in vivo ${ }^{34), 35)}$ is now well demonstrated. Dendritic cells generated from monocytes isolated from leprosy patients was more eficient to present $M$. leprae antigen to T cells ( $\alpha<$ 0.05 ) compared to the monocytes which failed to act as accessory cells (Figure 1 and 2). Our results are in agreement with the findings of Mittal, A. \& Nath, I. ${ }^{33)}$ who demonstrated the important role of dendritic cells as APC in T cell response in leprosy. Perhaps,



Figure 1. Anti-CD80 Ab and anti-CD86 Ab inhibit the proliferative response of PBMC to M. leprae. PBMC / well were cultured in the presence or not of $M$. leprae $(20 \mathrm{ug} / \mathrm{ml})$, plus or minus anti-CD80 $\mathrm{Ab}$ and/or anti-CD86 $\mathrm{Ab}(1 \mathrm{ug} / \mathrm{ml})$. AP, AF, OC...mean the initials of the patients studied. 
in addition to a distinct accessory cell requirement, $\mathrm{T}$ cell responses to $M$. leprae in LL patients become detectable only in the absence of monocytes which had been shown earlier to release factors that inhibited the immune response ${ }^{36}$ ). We observed that the use of in vitro dendritic cells as APC reversed the $M$. leprae - T cell hyporesponsiveness seen in LL patients. $T$ cells from these patients may require dendritic cells and not monocytes for the induction of proliferation.

It is now clear that the full $\mathrm{T}$ cell activation is generated by the interaction of CD28 on the T cells with CD80 and CD86 on APC. Our results show that the strongest blocking effect on $\mathrm{M}$. leprae- induced $\mathrm{T}$ cell activation was observed when anti-CD86 Ab was used (Figure 2).

The role of CD 80 and CD28 molecules in immunosupression in leprosy was recently reported by Agrewala, J.N. et al. ${ }^{28}$. They concluded that down regulation of $\mathrm{CD} 80$ and $\mathrm{CD} 28$ in lepromatous leprosy patients may be responsible for a defective $\mathrm{T}$ cell signalling by the CD80/CD28 pathway caused by $M$. leprae antigens. Similarly, the effect of CD80 in the M. leprae - specific immunesupression in leprosy was also demonstrated by us. However we demonstrated that $\mathrm{T}$ cell proliferation in leprosy was much more reduced by blocking CD86 pathway (Figure 2 ). Saha,B. et al. ${ }^{37)}$ have demonstrated that upon infection with Mycobacterium tuberculosis, $\mathrm{CD} 80$ was down-regulated in BALB/c mice but not in $\mathrm{C} 3 \mathrm{H} / \mathrm{Hej}$ mice. They suggest that this change in CD80 expression resuited in inhibition of DTH-mediating functions of Thelper cells from $B A L B / c$ mice. Initial studies using specific anti-CD80 Ab or antiCD86 to prevent various disease provide conflicting data depending upon the model. For example, in the auto-immune Diabetes, treatment of NOD mice with anti-CD86 Ab ameliorated disease, whereas anti-

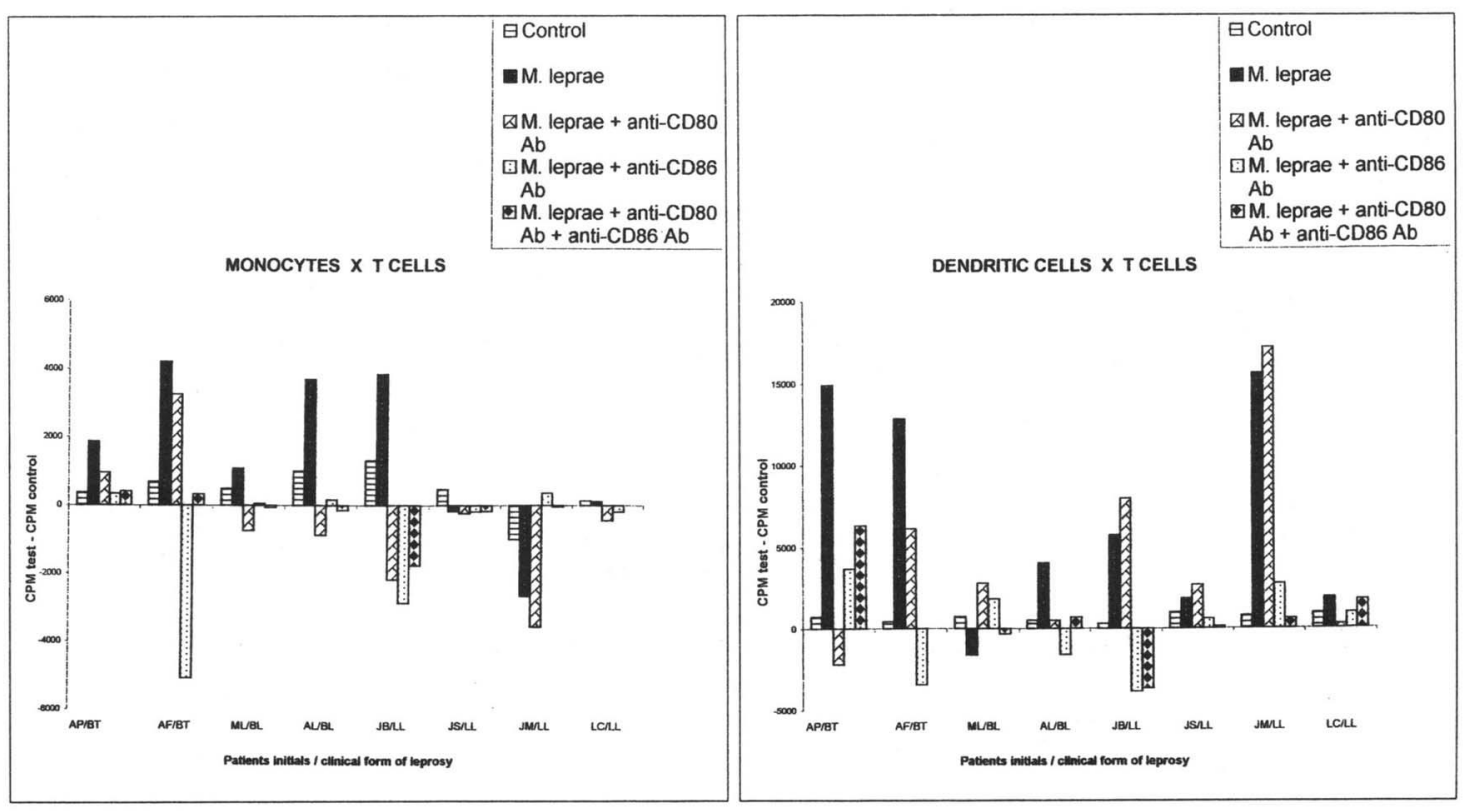

Figure 2. T cell response to $M$. leprae is more efficiently induced by dendritic cells than monocytes. Autologous T cells were cultured in presence or not of $M$. leprae $(20 \mathrm{ug} / \mathrm{ml})$ with monocytes or dendritic cells as APCs, plus or minus anti-CD80 $\mathrm{Ab}$ and/or anti-CD86 Ab (1ug/ml). 
$\mathrm{CD} 80 \mathrm{Ab}$ worsened disease ${ }^{38)}$. In leishmaniasis, Michaella Murphy et al. ${ }^{39)}$ reported the raise of T cell responses to Leishmania donovani by blocking CD86 pathway .

In other system (mouse EAE), administration of anti$\mathrm{CD} 80 \mathrm{Ab}$ was effective in preventing disease while administration of anti- CD86 worsened disease. Furthermore, in vitro addition of anti - CD80 Ab to T helper precursor cells promoted the production of the Th2 cytokines, while anti - CD86 Ab increased the production of the Th1 cytokines as gamma-IFN ${ }^{40}$. Finally, our results suggest that the existence of functionally diverse APC type (dendritic cells instead monocytes) provides an opportunity for the immunoregulation in leprosy. We have demonstrated that both costimulatory molecules (CD80 and CD86) may play a role in the immunopathology of leprosy although CD86 seems to preferentially act as a main costimulator for the generation of $M$. leprae-specific immune response in leprosy.

\section{Acknowledgments}

We are grateful to Dr. Cristina Pessolani for helping in obtaining $M$. Leprae antigen from Dr. Patrick Brenan and Hugo Walter for scientific discussions. This work was supported by grant from World Health Organization (ID 931100 ) and by some donations from Innogenetics N.V. We are also grateful to Jonatan Salles da Silva for graphic work and Dr. Ana Beatriz Soares Monteiro for the statistical analysis. We also thank the staff of Santa Casa da Misericórdia do $\mathrm{RJ}$ for patient care and providing us with the clinical data.

\section{References}

1) Ridley, D.S. \& Joplin, W. H. :Classification of leprosy according to immunity: A five group system. Int. J. Lepr. 34 , 255-263 (1966).

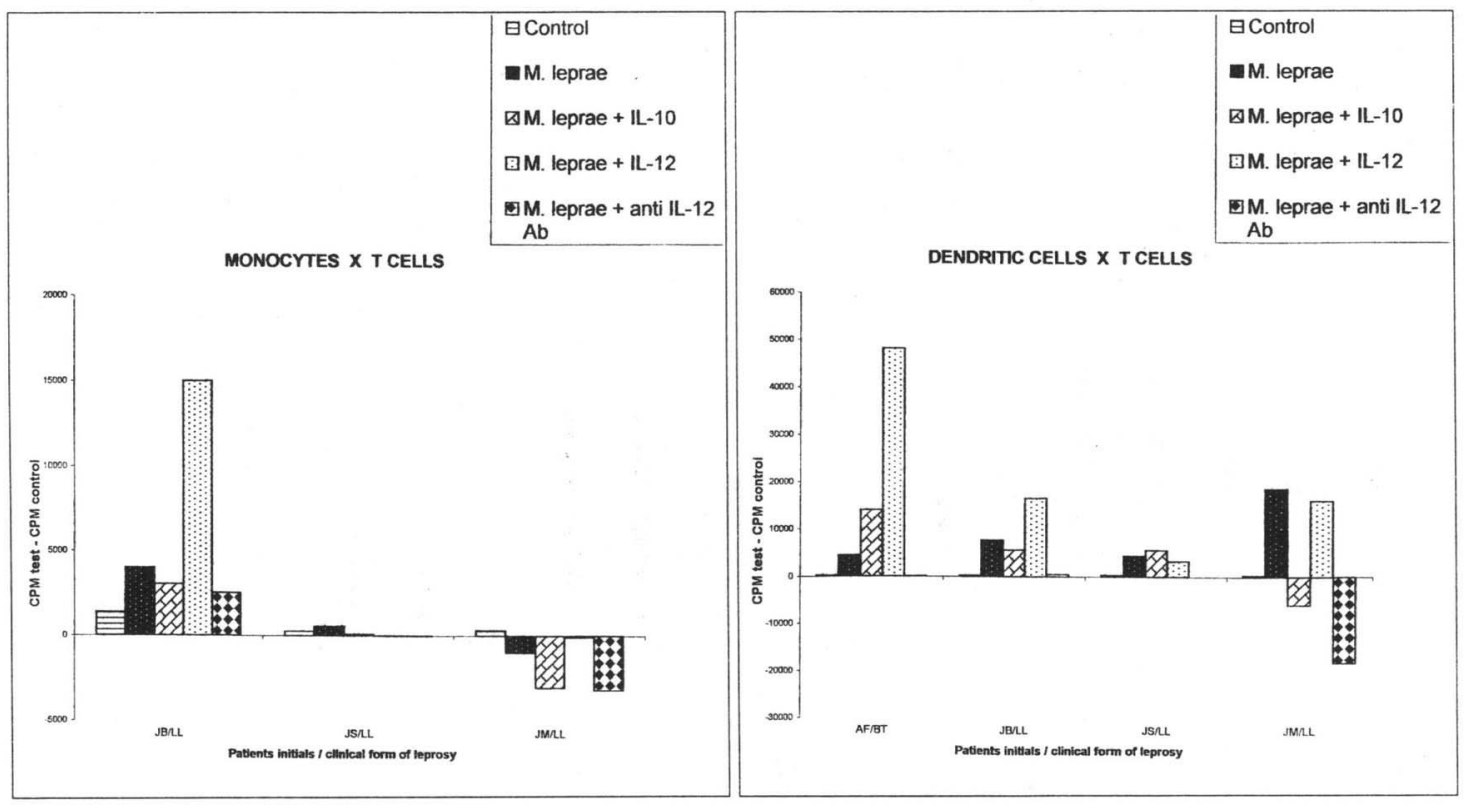

Figure 3. T cell proliferation in presence of $M$. leprae by using monocytes or dendritic cell as antigen - presenting cells. Monocytes or dendritic cells were cultured with autologous T cells in presence or not of M. leprae $(20 \mathrm{ug} / \mathrm{ml}) ; \mathrm{IL}-10(20 \mathrm{ng} /$ $\mathrm{ml}) ; \mathrm{IL}-12$ (10 ng/ml); anti-IL-12 Ab (10 ug/ml). 
2) Yamamura , M. et al. : Defining protective responses to pathogenic cytokine profiles in leprosy lesions. Science 254, 277-279 (1991).

3) Lenschow, D. \& Bluestone, J. A. : CD28 / B7 system of $\mathrm{T}$ cell costimulation. Annu. Rev. Immunol. 14 ,233-258 (1996).

4) Hansen, J. A. P.J. et al.: Monoclonal antibodies identifying a novel $\mathrm{T}$ cell antigen and Ia antigens of human lymphocytes. Immunogenetics $10,247-252$ (1980).

5) Haring, F.A. et al.: CD28-mediated signalling costimulattes murine $T$ cells and prevents induction of anergy in T cell clones. Nature 356, 607610 (1992).

6) Harper, M. et al.: CTLA-4 and CD28 activated lymphocyte molecules are closely related in both mouse and human as to sequence, message expression, gene structure and chromossomal location. J.Immunol. 147, 1037-1044 (1991).

7) Linsley, P.S. et al.: Coexpression and functional cooperation of CTLA-4 and CD28 or activated T lymphocytes. J. Exp. Med. 176, 1595-1600 (1992).

8) Walunas, T. L. : CTLA-4 can function as a negative regulator of $\mathrm{T}$ cell activation.Immunity 1 , 405-413 (1994).

9) Freeman, A.S. et al.: B7, a new member of the Ig superfamily with unique expression on activated and neoplastic B cells. J. Immunol. 143 , 274-2722 (1987).

10) Freeman, G. J. et al.: Murine B7-2, an alternative CTLA-4 counter-receptor that costimulates T cell proliferation and interleukin-2 production . J. Exp. Med. 178, 2185-2192 (1993).

11) Azuma, M.M. et al.: Requirements for CD28dependent $\mathrm{T}$ cell-mediated cytotoxicity. J. Immunol. 156 , 2091-2095 (1993).

12) Linsley, P. S. W. et al.: T cell antigen CD28 mediates adhesion with $\mathrm{B}$ cells by interacting with activation antigen B7/BB1. Proc. Natl. Acad. Sci. (USA) 87, 5031-5035 (1990).

13) Linsley,P.S.W. et al.: CTLA-4 is a second receptor for the B cell activation antigen B7. J. Exp.
Med. 174, 561-567 (1995).

14) Freeman, G.J. et al.: Uncovering of functional alternative CTLA-4 counter-receptor in B7-deficient mice. Science 262 , 907-909 (1993).

15) Freeman, G.J. et al. : Cloning of B7-2: a CTLA4 counter-receptor that costimulates human $\mathrm{T}$ cell proliferation. Science 262 , 909-911 (1993).

16) Nabavi, N. et al.: Signalling through the MHC class II cytoplasmic domain is required for antigen presentation and induces B7 expression. Nature 360, 266-268 (1992).

17) Hathcock et al.: Identification of an alternative CTLA-4 ligand costimulatory for T cell activation. Science 262 , 905-907 (1993).

18) Hathcock, K. S. et al.: Comparative analysis of B7-1 and B7-2 costimulatory ligands: expression and function. J. Exp. Med. 180, 631-640 (1994).

19) Boussiotis, V.A. et al.: Activated human B lymphocytes express three CTLA-4 counterreceptors that costimulate T cell activation. Proc. Natl. Acad. Sci. 90 , 11059-11063 (1993).

20) Bhardwaj et al. :Dendritic cells are potent antigen-presenting cells for microbial superantigens. J.Exp. Med. 175 , 267-273 (1992).

21) Sallusto, F. et al.: Dendritic cells use macropinocytosis and manose receptor to concentrate macromolecules in the major histocompatibility complex class II compartment: Downregulation by cytokines and bacterial products. J. Exp. Med. 182 , 389-400 (1995).

22) Roake et al.: Dendritic cells loss from nonlymphoid tissues after systemic admistration of lipopolysacharide, TNF and IL-1. J. Exp. Med. 181, 2237-2247 (1995).

23) Macatonia , S.E.et al.: Dendritic cells produce IL-12 and direct the development of Th1 cells from naive CD4+ T cells. J. Immunol. 154, 50715079 (1995).

24) Scheicher et al.: Uptake of microparticleabsorved protein antigen by bone marrow Dendritic cells results in upregulation of IL-12 and IL-12 p40/p35 and triggers prolonged efficient antigen presentation. Eur. J. Immunol. 25 , 1566- 
$1572(1995)$.

25) Cella,M. et al.: Ligation of CD40 on dendritic cells triggers production of high levels of IL-12 and enhances $\mathrm{T}$ cell stimulatory capacity: T-T help via APC activation. J. Exp. Med. 184, 747752 (1996).

26) Shen, L. et al.: Glucocorticoid enhances gammainterferon effects on human monocyte antigen expression and ADCC. Clin. Exp. Immunol. $65,387-392$ (1986).

27) Santos, D.O. et al.: Evaluation of chemiluminescence, procoagulant activity and antigen presentation by monocytes from lepromatous leprosy patients with or without reactional episodes. Lepr. Rev. 65, 88-99 (1994).

28) Noether, G.E. Introduction to Statistics: A Nonparametric Approach 1983. Ed. Guanabara Dois S.A. ( Traduced by Flávio Rodrigues and Lisbeth K. Cordani. 2nd. Edition)

29) Agrewala, J.N. et al. : Potencial role of B7-1 and $\mathrm{Cd} 28$ molecules in immunosuppression in leprosy. Clin. Exp. Immunol. 111 , 56-63 (1998).

30) Trinchieri, G. et al.: Interleukin-12 and its role in the generation of Th1 cells. Immunol. Today 14 , 335-338 (1993).

31) Steinman,R.M. et al. : Signals arising from antigen presenting cells. Curr. Opin. Immunol. 3 , 361-368 (1991)

32) Cameron, P.U. et al. :Dendritic cells exposed to human immunodeficiency virus type-1 transmit a vigorous cytopathic infection to CD4+Tcells. Science 257 , 383-386 (1992).

33) Mittal, A. \& Nath, I.: Accesssory cell heterogeneity in lepromatous leprosy; dendritic cells and not monocytes support $\mathrm{T}$ cell responses. Clin. Exp. Immunol. 76 , 233-239 (1989).

34) Sornasse,T. et al. : Antigen-pulsed dendritic cells can efficiently induce an antibody response in vivo. J. Exp. Med. 175 , 15-20 (1992).

35) Demangel,C. et al. : Protection against aerosol Mycobacterium tuberculosis infection using Mycobacterium bovis Bacillus Clamette Guerin-infected dendritic cells . Eur. J. Immunol. 29 , 1972-1979 (1999).

36) Nath,I. et al.: Inhibition of Interleukin-2 production by adherent cell factors from lepromatous leprosy patients . Clin. Exp. Immunol. 58, 531536 (1984a).

37) Saha,B. et al.: Macrophage-T cell interaction in experimental mycobacterial infection. Selective regulation of costimulatory molecules on $\mathrm{My}$ cobacterium infected macrophages and its implication in the suppression of cell-mediated immune response. Eur. J. Immunol. 24 , (11), 2618-2624 (1994).

38) Lenschow, D. J. et al.: Differential effects of antiB7-1 and anti-B7-2 monoclonal antibodiy treatment on the development of diabetes in the nonobese diabetic mouse. J.Exp. Med. 181, 1145 1151 (1995).

39) Murphy, M. et al.: B7-2 blockade enhances T cell responses to Leishmania donovani.J. Immunol. 159, 4460-4466 (1997).

40) Kuchroo,V.K.et al.: B7-1 and B7-2 costimulatory molecules activate differentially the Th1/Th2 developmental pathways: application to autoimmune disease therapy. Cell 80 , 707-712 (1995). 